\title{
Pneumatic Conveying of SeEd CotTon: MINIMUM VELOCITY AND PRESSURE DROP
}

\author{
R. G. Hardin IV
}

\begin{abstract}
Electricity is a major cost for cotton gins, representing approximately $20 \%$ of variable costs. Fans used for pneumatic conveying consume the majority of electricity at cotton gins. Development of control systems to reduce the air velocity used for conveying seed cotton could significantly decrease electricity use and cost. A greater understanding of the pneumatic conveying characteristics of seed cotton is necessary for development of these systems. A negative pressure conveying system was constructed with a feed control, conveying pipe, separator, and fan. Air velocity was measured at the system inlet and in the conveying section when testing with air only. A differential pressure measurement was taken in the conveying pipe, and temperature and relative humidity were recorded. Two pipe diameters, two cultivars, two moisture content levels, and three seed cotton feed rates were included in the experimental design. Seed cotton was fed into the conveying system, and the fan speed was decreased until choking occurred. The minimum differential pressure measurement indicated the saltation velocity. A segmented linear model was fit to the log transformed data to identify the mass flow ratio and Froude number $(\mathrm{Fr})$ corresponding to the minimum pressure. This model accurately fit the data $\left(R^{2}=0.88\right)$ and resulted in the following equation for finding the saltation velocity: $\phi=8.90 \times 10^{-5} \times \mathrm{Fr}_{\min }{ }^{5.04}$, where $\mathrm{Fr}_{\text {min }}$ is the Fr at the saltation velocity. The solids resistance factor at velocities greater than saltation was found to be $0.179 \times \mathrm{Fr}^{-1}$. This model had an $R^{2}$ of 0.91 and predicted the pressure drop with $14.2 \%$ error. Pipe diameter, cultivar, and moisture content level did not have a practically significant effect on the models developed to predict saltation velocity or the solids resistance factor. These models may be useful in designing control systems for cotton gin conveying systems, resulting in significant electricity and cost savings.
\end{abstract}

Keywords. Conservation, Cotton, Electricity, Energy, Ginning, Pneumatic conveying, Saltation velocity.

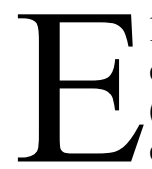
lectricity is a significant cost for cotton gins, accounting for approximately $20 \%$ of variable costs (Valco et al., 2012). Over half of the electricity consumed at gins is used by centrifugal fans for pneumatic conveying (Funk and Hardin, 2012; Hardin and Funk, 2012). For a centrifugal fan, the volumetric flow rate and air velocity vary linearly with the fan speed. When moving air only, the pressure drop is proportional to the square of the fan speed, and the power consumed is proportional to the fan speed cubed. When conveying material, components of the total system pressure drop also include the acceleration of the conveyed material and the resistance of the conveyed solids. For a constant solids mass flow rate, the pressure drops due to acceleration and resistance of the conveyed solids are not proportional to the fan speed squared. However, for most gin systems, the total pressure drop will be nearly proportional to the velocity squared. Consequently, a

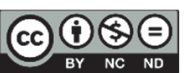

The authors have paid for open access for this article. This work is licensed under a Creative Commons Attribution-Non Commercial-NoDerivatives 4.0 International License https:// creative commons.org/licenses/by-nc-nd/4.0/

Submitted for review in September 2013 as manuscript number PM 10437; approved for publication by the Power \& Machinery Division of ASABE in April 2014.

Mention of a trade name, proprietary product, or specific equipment does not constitute a guarantee or warranty by the USDA and does not imply approval of the product to the exclusion of others that may be available. The USDA is an equal opportunity provider and employer.

The author is Robert G. Hardin IV, ASABE Member, Research Physical Scientist, USDA-ARS Cotton Ginning Research Unit, 111 Experiment Station Rd. Stoneville, MS 38776; phone: 662-686-3096; email: bobby.hardin@ars.usda.gov. small reduction in fan speed and air velocity can greatly reduce energy requirements and could produce significant cost savings at cotton gins. Advances in control technologies, primarily the development of lower-cost adjustable-speed drives for AC motors, could make fan speed control feasible in cotton gins. However, further research on pneumatic conveying systems for seed cotton, lint, seed, and foreign matter in cotton gins is needed for the development of these control systems.

\section{LITERATURE REVIEW}

Mangialardi (1977) tested different combinations of air velocities and seed cotton mass flow rates to identify conditions resulting in successful horizontal conveyance of seed cotton in a $20.3 \mathrm{~cm}$ (8 in.) diameter pipe. Observations of the conveyed seed cotton were made through clear sections of pipe, and the flow was described as: normal, sluggish but all seed cotton moving in the air stream, some seed cotton falling out of suspension and remaining at the bottom of the pipe without choking, or plugging the pipe. The required air velocity to maintain normal flow was determined to be $12.7 \mathrm{~m} \mathrm{~s}^{-1}$ ( 2500 $\mathrm{ft} \mathrm{min}^{-1}$ ) at a mass flow ratio (mass flow rate of seed cotton divided by mass flow rate of air) of 1.33 and a moisture content of $20 \%$ (w.b.) and $9.1 \mathrm{~m} \mathrm{~s}^{-1}\left(1800 \mathrm{ft} \mathrm{min}^{-1}\right)$ at a mass flow ratio of 1.03 and a moisture content of $10 \%$. The minimum required air velocity decreased with mass flow ratio and moisture content, although no relationship was developed between these variables. 
However, these air velocities were the measured velocities in the conveying section before seed cotton was introduced into the experimental apparatus. The actual velocities would be less, as the system pressure drop would increase due to the conveyed solids, resulting in a shift in the operating point on the fan curve. Consequently, the minimum velocities reported by Mangialardi (1977) are affected by fan selection and system design, as well as mass flow ratio and moisture content, and are not directly applicable to other seed cotton conveying systems. Current recommendations for conveying air velocities for seed cotton are between 17.8 and $25.4 \mathrm{~m} \mathrm{~s}^{-1}$ (3500 and $5000 \mathrm{ft} \mathrm{min}^{-1}$ ) (Baker et al., 1994). These values are higher than the minimum velocities identified by Mangialardi (1977). Wide variations in instantaneous material flow rate occur with the feed control systems in cotton gins (R. G. Hardin, USDA-ARS, unpublished data), and the moisture content of the incoming material can rapidly increase when a wet region in a module is encountered (Byler and Anthony, 2000; Hardin and Funk, 2013). Using the minimum required conveying velocity for average conditions would result in choking if the material flow rate or moisture content increased. Without an air velocity control system, higher velocities must be used to account for these fluctuations in material flow rate and moisture content.

No data have been reported on the additional pressure drop due to solids when conveying seed cotton. Typical design procedures for conveying systems in cotton gins (Holt et al., 2001) only consider the frictional losses due to air. When conveying material, the pressure drop will be larger and the air velocity lower than predicted. This uncertainty in gin plant design may lead to reduced plant efficiency.

Researchers have studied pneumatic conveying of other materials, such as sand, glass beads, and seeds, and developed relationships between air velocity, air density, pressure drop, mass flow ratio, and pipe diameter. Although the materials used to develop these models were nearly spherical and homogenous, these relationships may still be applicable to seed cotton. Zenz (1949) conducted experiments to characterize the pressure drop per unit length over a range of air velocities and mass flow ratios when conveying a variety of materials, including rapeseed. Zenz developed phase diagrams showing that the pressure drop per unit length decreases with decreasing velocity, reaches a minimum, and then increases as velocity is decreased further. In horizontal conveying, the velocity at which the minimum pressure occurs is known as the saltation velocity and corresponds to the minimum conveying velocity. The increase in pressure at lower velocities is due to increased friction as solid material falls out of suspension to the bottom of the pipe (saltation refers to the lifting of particles by the air stream and subsequent deposition). Conveying systems in gins are designed to be operated with mass flow ratios of 0.33 to 0.67 (Baker et al., 1994). The ginning industry often uses a ratio of the volumetric flow rate of air to the mass flow rate of seed cotton; these mass flow ratios are equivalent to 20 to $40 \mathrm{ft}^{3} \mathrm{lb}^{-1}$. These mass flow ratios correspond to operation in the dilute phase (Klinzing et al., 2010) at velocities higher than the saltation velocity.

Experimental evidence has shown that the saltation ve- locity is influenced by the mass flow ratio and the pipe diameter. Barth (1954) suggested that the mass flow ratio is proportional to the fourth power of the Froude number related to air velocity $(\mathrm{Fr})$ at saltation $\left(\mathrm{Fr}=v(g D)^{-0.5}\right.$, where $v$ is the air velocity, $g$ is the acceleration due to gravity, and $D$ is the pipe diameter. Use of the Froude number in this article is the Froude number related to air velocity). Welschof (1962) proposed a more general power law relationship in which the exponent varies for different conveyed materials. Later researchers developed a number of equations designed for use with any conveyed material that included parameters such as particle diameter, terminal velocity, and solids density. Jones and Leung (1978) compared the accuracy of a number of these relationships for predicting the saltation velocity of different materials. The relationship with the lowest error was the most complex and required an iterative procedure to determine saltation velocity; however, several simpler equations performed nearly as well. These included equations developed by Mewing (1976), Matsumoto et al. (1975), and Rizk (1976), all of which followed a power law relationship between the mass flow ratio and the Froude number at saltation velocity. While these models are useful for application to materials for which no experimental data exist, more accurate equations specific to individual materials can be developed through testing.

For dilute-phase steady-state conveying in a horizontal pipe, the pressure drop is due to the friction of the conveying air (given by Darcy's equation) and the combined effects of friction, impact, and gravity on the solid particles. A number of expressions have been developed to predict the pressure drop due to resistance of the conveyed solids; these are generally presented in the following form, similar to Darcy's equation:

$$
\frac{\Delta p_{s}}{L}=\frac{\phi \lambda_{s} \rho v^{2}}{2 D}
$$

where

$\Delta p_{s} / L=$ pressure drop due to solids per unit length $\left(\mathrm{Pa} \mathrm{m}^{-1}\right)$

$\phi=$ mass flow ratio

$\lambda_{s}=$ resistance factor for solids

$\rho=$ fluid density $\left(\mathrm{kg} \mathrm{m}^{-3}\right)$

$v=$ fluid velocity $\left(\mathrm{m} \mathrm{s}^{-1}\right)$

$D=$ pipe diameter $(\mathrm{m})$.

Studies measuring the pressure drop when conveying grain found that $\lambda_{s}$ varied inversely (or nearly so) with air velocity (Crane and Carleton, 1957; Person and Sorenson, 1966); however, these studies only tested a single pipe diameter, so the influence of this variable could not be evaluated. Later researchers (Chand and Ghosh, 1968; Konno and Saito, 1969) derived expressions for $\lambda_{s}$ that were inversely related to the Froude number. This dimensionless number represents the ratio of the inertial force acting on an object to the gravitational force; consequently, the influence of the Froude number on the pressure drop is not surprising. The gravitational force affects the energy required to lift particles off the bottom of the pipe back into the air stream. Additionally, the amount of energy lost due to particle-particle and particle-wall friction will be proportional to the normal force 
acting on the particles, which will be affected by the weight of the particles.

\section{OBJECTIVES}

The goal of this research was to develop an improved understanding of the pneumatic conveying characteristics of seed cotton so that cotton gin conveying systems can be designed that use the minimum air velocities required for reliable operation and efficient drying, thus reducing energy use. Furthermore, improved gin conveying systems should reduce the likelihood of choking during adverse conditions. Specific objectives were:

- Develop a model for predicting the saltation velocity of seed cotton.

- Develop a model to predict $\Delta p_{s} / L$ in the conveying line for dilute-phase steady-state conveying.

- Determine the effects of pipe diameter, cultivar, and moisture content on the saltation velocity and pressure drop due to solids resistance.

\section{Materials ANd Methods Pneumatic Conveying System}

A negative-pressure conveying system was constructed. Figure 1 shows the inlet pipe and seed cotton feeding apparatus. The inlet pipe was $3.05 \mathrm{~m}(10 \mathrm{ft})$ long and had a diameter of $25.4 \mathrm{~cm}$ (10 in.). A miniature pitot tube (166-12-CF, Dwyer Instruments, Inc., Michigan City, Ind.) was installed $2.16 \mathrm{~m}$ (85 in.) from the inlet. All velocity pressures were measured with Dwyer 607D-05 differential pressure transmitters. Seed cotton was placed into the loading chute above

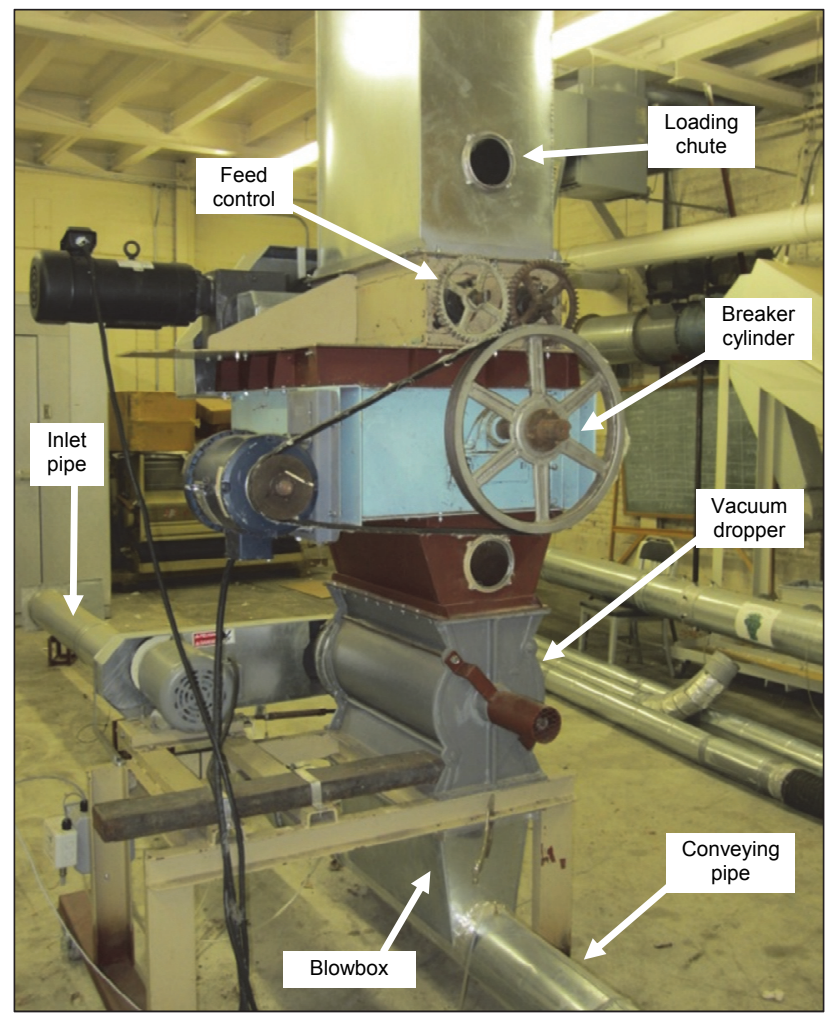

Figure 1. Seed cotton feeding apparatus. Guards on rotating machinery removed for visibility. the feed control rollers. Feed control roller speed was adjusted using a variable-speed DC motor. A breaker cylinder was installed to disperse the seed cotton, similar to many steady-flow feed controls in commercial gins. A $61 \mathrm{~cm} \mathrm{(24}$ in.) long by $30.5 \mathrm{~cm}$ (12 in.) diameter vacuum dropper was located immediately below the breaker cylinder to minimize air leakage.

A parallel-flow blowbox was located under the vacuum dropper. Two diameters of conveying pipes were used: $17.8 \mathrm{~cm}$ (7 in.) and $25.4 \mathrm{~cm}$ (10 in.); consequently, each diameter required a separate blowbox. When using the smaller-diameter conveying pipe, a transition was installed between the inlet pipe and blowbox.

The conveying pipe traversed $7.92 \mathrm{~m}$ (26 ft) horizontally. Another miniature pitot tube was installed in the conveying pipe ten diameters downstream from the end of the blowbox. Velocity measurements with this pitot tube were made with air only and used to quantify air leakage through the seed cotton feeding apparatus. When conveying seed cotton, the pitot tube was removed and a plug installed in the fitting. The air velocity in the conveying pipe was calculated from the measured air velocity in the inlet pipe and the air leakage through the seed cotton feeding apparatus. This estimated conveying pipe velocity was used in all subsequent analysis.

A piezometer ring was installed 20 diameters downstream from the blowbox, and a second ring was located five diameters downstream from the first (fig. 2). The piezometer rings were connected to $1.45 \mathrm{~L}$ (0.384 gal) air chambers to dampen pressure fluctuations, so the measured differential pressure remained within the range of the Dwyer 607D-03 differential pressure transmitter. A clear acrylic viewing spool was installed a minimum of two diameters after the second piezometer ring, before an elbow and vertical pipe. Material flow was observed through the clear section and classified into the following categories: (A) normal, evenly distributed flow; (B) more material in the bottom half of the pipe, but all material flowing in the air stream; (C) material settled on the bottom of the pipe, but flowing above; and (D) settled material on the bottom of the pipe, forming slugs. This visual classification was performed by the same person

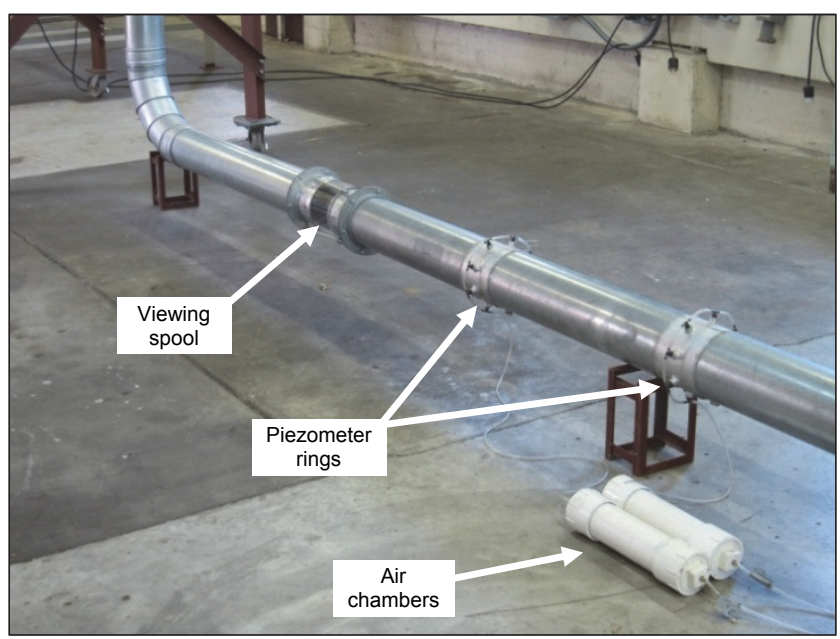

Figure 2. Conveying pipe (looking downstream toward elbow and vertical pipe). 


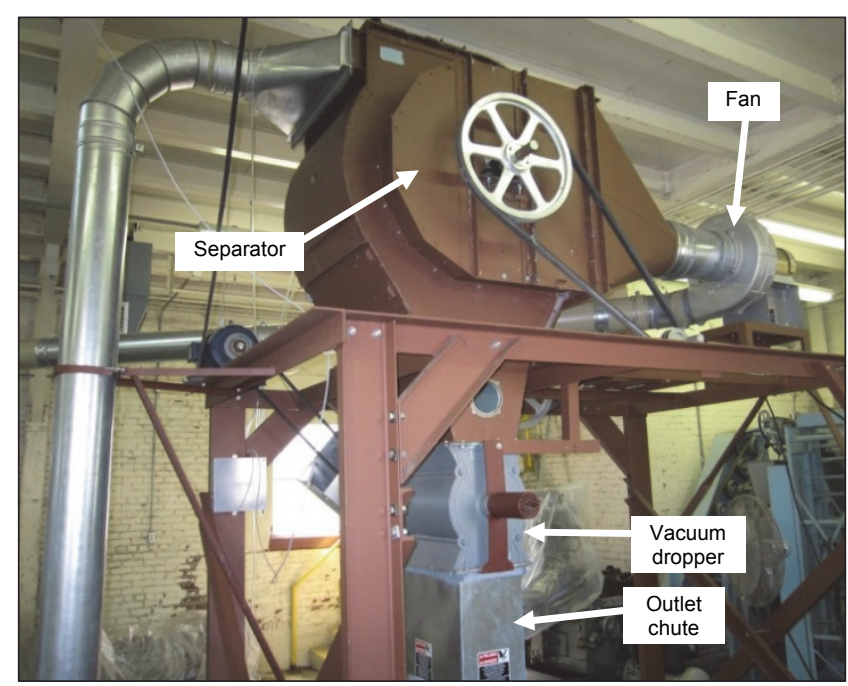

Figure 3. Separator and fan for conveying system.

for all tests and was done to compare results with the Mangialardi (1977) study.

The $3.35 \mathrm{~m}$ (11 ft) long vertical pipe was followed by an elbow and transition to a revolving drum separator with a 61 $\mathrm{cm}$ (24 in.) long by $30.5 \mathrm{~cm}$ (12 in.) diameter vacuum dropper at the seed cotton outlet of the separator (fig. 3). A $45 \mathrm{~cm}$ (18 in.) long outlet chute was installed below the vacuum dropper for safety, and seed cotton was collected in bags at the bottom of the chute. A radial-blade centrifugal fan (PB$15 \mathrm{~A}$, Cincinnati Fan, Mason, Ohio) was connected to the separator air exhaust. Fan speed, and consequently, air flow and velocity, was controlled using a variable-frequency $\mathrm{AC}$ drive. The differential pressure across the fan was measured with a Dwyer 616-4 differential pressure transmitter, and fan electrical power was measured with a WattsOn 1200-5A power transducer (Elkor Technologies, Inc., London, Ontario, Canada) and Magnelab MGC-1000-100 current transformers (Magnelab, Inc., Longmont, Colo.). The conveying air was exhausted into a settling chamber through a $20.3 \mathrm{~cm}$ (8 in.) diameter pipe.

A Dwyer RHP-2S11 temperature and relative humidity transmitter was installed on the frame of the seed cotton feeding apparatus. Sensor data were collected at $0.01 \mathrm{~s}$ intervals using the MATLAB Data Acquisition Toolbox (MATLAB R2011a, Mathworks, Inc., Natick, Mass.) and a multifunction data acquisition device (USB-1408FS, Measurement Computing Corp., Norton, Mass.).

\section{TESTING}

A hairy-leaf cultivar, ST 4554 B2RF (Bayer CropScience, Research Triangle Park, N.C.), and a smooth-leaf cultivar, DP 161 B2RF (Monsanto, St. Louis, Mo.), were used in the study. Cultivars with different foreign matter contents were selected, as the quantity of foreign matter may influence the pneumatic conveying characteristics of the seed cotton. One sample from each test lot was collected for foreign matter content determination (Shepherd, 1972). Foreign matter content of the cultivars was significantly different, averaging $7.56 \%$ for the ST $4554 \mathrm{~B} 2 \mathrm{RF}$ and $6.49 \%$ for the DP 161 B2RF. Two moisture conditioning treatments were used, as half of the seed cotton was allowed to equilibrate with the ambient atmosphere and the other half was stored at a constant $85 \%$ relative humidity. Three samples were collected from each test lot for moisture content determination by oven drying (Shepherd, 1972). The resulting average moisture contents were significantly different between the treatments, with an average moisture content of $8.2 \%$ (w.b.) for the seed cotton stored at ambient conditions and $11.1 \%$ for the seed cotton stored at $85 \%$ relative humidity. Three feed rates, averaging 17.8, 38.4, and $59.4 \mathrm{~kg} \mathrm{~min}{ }^{-1}$ $\left(39.3,84.6\right.$, and $\left.131.0 \mathrm{lb} \mathrm{min}^{-1}\right)$, were achieved by varying the feed control roller speed and included in the study. The average coefficient of variation across all feed rates was $7.3 \%$. The experiment was a split-plot design, with three replications used as main blocks, the duct diameter as the subblock, and a factorial combination of cultivar, moisture conditioning treatment, and feed rate tested within each subblock. Once within each sub-block (diameter $\times$ replication combination), the system was operated at multiple velocities with air only.

The seed cotton used was weighed prior to loading into the pneumatic conveying system. The amount used varied with the feed rate, as higher feed rates required more cotton to ensure that choking occurred before all material was conveyed. The average lot sizes were 43.0, 72.8, and $98.2 \mathrm{~kg}(94.8$, 160.5 , and $216.5 \mathrm{lb}$ ) for the low, medium, and high feed rates. For each test lot, the feed control was started immediately prior to starting the data acquisition system. Fan speed was initially $3490 \mathrm{rpm}$ (directly driven from the motor at $60 \mathrm{~Hz}$ ), decreased to $3050 \mathrm{rpm}$, reduced to $2620 \mathrm{rpm}$, and thereafter decreased by $90 \mathrm{rpm}(2.5 \%$ of initial fan speed). Fan speed was decreased until the conveying pipe choked. For the aironly tests, fan speed was decreased to $25 \%$ of the initial fan speed in the same manner. Data were collected for $4 \mathrm{~s}$ and averaged at each fan speed, with $2 \mathrm{~s}$ allowed for achieving steady-state conditions after changing fan speeds. Choking was indicated by an absence of material flow in the clear observation section. When choking occurred, the feed control was stopped and the fan speed increased to $3490 \mathrm{rpm}$. This maximum fan speed was usually sufficient to re-entrain the seed cotton in the air stream. Any seed cotton remaining in the pipe was manually removed before restarting the feed control to convey the remaining seed cotton for that lot. The total time that cotton was fed into the pneumatic conveying system (both before and after choking) was recorded to determine the actual feed rate.

\section{DETERMINATION OF SALTATION VELOCITY}

The saltation velocity, corresponding to the minimum differential pressure drop in the conveying pipe at a given mass flow ratio, was identified initially to distinguish dilute and dense phase conveying. However, the mass flow ratio increased during testing of each lot because the seed cotton mass flow rate remained constant while the air velocity and flow rate decreased. As a result, a method was developed using nonlinear regression (PROC NLIN, SAS 9.2, SAS Institute, Inc., Cary, N.C.) to identify parameters in a saltation velocity model.

A segmented model, with separate equations for dilute 
and dense phase conveying, was used to describe the pressure drop per unit length in the conveying pipe. The intersection of the two segments corresponded to the minimum pressure drop and the saltation velocity. The total pressure drop per unit length in steady-state dilute-phase conveying could be found from equation 1 and Darcy's equation; however, the relationship between pressure drop, Froude number, and mass flow ratio is not well understood for densephase conveying. Therefore, the dependent variable (pressure drop per unit length) and independent variables (Froude number and mass flow ratio) were log transformed to linearize the expressions for both dense and dilute phase conveying (eq. 2):

$\ln \left(\frac{\Delta p}{L}\right)=\left\{\begin{array}{l}c_{1} \ln \mathrm{Fr}+c_{2} \ln \phi+c_{3}, \mathrm{Fr} \geq \mathrm{Fr}_{\min } \text { (dilute phase) } \\ c_{4} \ln \mathrm{Fr}+c_{5} \ln \phi+c_{6}, \mathrm{Fr}<\mathrm{Fr}_{\min } \text { (dense phase) }\end{array}\right.$

where

$\Delta p / L=$ total pressure drop (due to resistance of air and solids) per unit length $\left(\mathrm{Pa} \mathrm{m}^{-1}\right)$

$c_{1}$ to $c_{6}=$ regression coefficients in segmented linear model.

The study by Jones and Leung (1978) indicated that a power law relationship between the mass flow ratio and the Froude number at the saltation velocity $\left(\mathrm{Fr}_{\mathrm{min}}\right)$ accurately describes the behavior of a variety of conveyed materials. To develop a more accurate model specific to seed cotton, the generalized relationship originally proposed by Welschof (1962) was used:

$$
\phi=k \mathrm{Fr}_{\min }^{\alpha}
$$

where $k$ and $\alpha$ are constants. Because the segmented linear model is continuous, the two piecewise functions are equivalent at $\mathrm{Fr}_{\mathrm{min}}$. By equating the two segments and using equation 3 to constrain the model, the following relationships were developed between the parameters of the saltation velocity model and the segmented linear model:

$$
\begin{array}{r}
\alpha=\frac{c_{1}-c_{4}}{c_{5}-c_{2}} \\
\ln k=\frac{c_{3}-c_{6}}{c_{5}-c_{2}}
\end{array}
$$

The effects of duct diameter, cultivar, and moisture conditioning treatment on the segmented linear model (eq. 2 constrained by eqs. 4 and 5) were determined using the method described by Hinds and Milliken (1987). For each treatment, the model was fit to each treatment level individually, as well as the combined data set. An F-test statistic was calculated using the regression sum of squares and degrees of freedom from the models of individual treatment levels and the combined data.

Logistic regression (PROC LOGISTIC) was used to predict which material flow category (A to D) resulted from tested combinations of mass flow ratios and Froude numbers. Because the boundaries between these categories were not adequately described by a linear combination of the mass flow ratio and Froude number, the log transformations of both variables were used as explanatory variables in the logistic regression models. The resulting equations describing the boundaries between the material flow categories follow the same power law relationship between the mass flow ratio and the Froude number as equation 3.

\section{Determination of Solids Resistance FACTOR}

After identifying the saltation velocity, the resistance factor for solids in dilute-phase conveying $\left(\lambda_{s}\right)$ was determined using nonlinear regression (PROC NLIN). For all data points with a velocity greater than the saltation velocity, the following model for pressure drop was used:

$$
\frac{\Delta p}{L}=\frac{\lambda_{a} \rho v^{2}}{2 D}+\frac{\phi \lambda_{s} \rho v^{2}}{2 D}
$$

where $\lambda_{a}$ is the resistance factor for air alone.

Since all conditions tested resulted in turbulent air flow, the resistance factor for air could be found from a Moody diagram or using the iterative Colebrook equation. However, for efficient computation in nonlinear regression, the following equation, proposed by Zigrang and Sylvester (1982), was used:

$$
\begin{aligned}
\frac{1}{\sqrt{\lambda_{a}}} & =-2 \log \left(\frac{\varepsilon}{3.7 D}-\frac{5.02}{\operatorname{Re}}\right. \\
& \left.\times \log \left[\frac{\varepsilon}{3.7 D}-\frac{5.02}{\operatorname{Re}} \log \left(\frac{\varepsilon}{3.7 D}+\frac{13}{\operatorname{Re}}\right)\right]\right)
\end{aligned}
$$

where

$$
\begin{aligned}
& \varepsilon=\text { absolute roughness of pipe material }(\mathrm{m}) \\
& \operatorname{Re}=\text { dimensionless Reynolds number; } \operatorname{Re}=\rho \nu D / \mu,
\end{aligned}
$$$$
\text { where } \mu \text { is dynamic viscosity (Pa s). }
$$

This equation was developed by iterating the Colebrook equation twice and then substituting an average value for the $\lambda_{a}$ term on the right side of the equation. This approximation has extremely low deviation $(<0.05 \%)$ from the Colebrook equation over the range of Reynolds numbers modeled $(95,000$ to 360,000$)$ and for absolute roughness values between 0.05 to $0.15 \mathrm{~mm}$, the range of roughness values likely encountered in gin conveying pipes.

The resistance factor for the solids was modeled by the following equation, suggested by a number of past researchers (Chand and Ghosh, 1968; Konno and Saito, 1969):

$$
\lambda_{s}=s \mathrm{Fr}^{-1}
$$

where $s$ is the proportionality constant for solids resistance. Equations 6, 7, and 8 comprise the pressure drop model for dilute-phase steady-state conveying. The effects of duct diameter, cultivar, and moisture conditioning treatment on the pressure drop model were determined using the same method (Hinds and Milliken, 1987) as with the saltation velocity model.

\section{RESULTS AND DISCUSSION}

\section{SALTATION VELOCITY}

The minimum pressure drop can be observed for each feed rate in figure 4. As expected, the differential pressure 
increased with increasing feed rates. Fewer data points were collected at velocities lower than the saltation velocity with the $17.8 \mathrm{~cm}$ (7 in.) pipe than the larger pipe. The same change in fan speed resulted in a larger decrease in air velocity with the $17.8 \mathrm{~cm}$ (7 in.) pipe; consequently, fewer measurements were made after the minimum pressure was reached before choking occurred. This result may have affected the accuracy of the model used to determine the saltation velocity (eq. 2 constrained by eqs. 4 and 5) because relatively few points were used to fit the dense phase region of the segmented model.

The segmented linear model (eq. 2 constrained by eqs. 4 and 5) had an $\mathrm{R}^{2}$ of 0.88 and $5.7 \%$ error with the log transformed data. The error for the actual pressure drop data (untransformed) was $15.4 \%$. However, the primary purpose of this model was to identify the combination of air velocity and feed rate that corresponded to the minimum pressure drop, not to accurately predict pressure (especially at pressures much higher than the minimum). The resulting relationship between the mass flow ratio and the Froude number at saltation velocity was obtained:

$$
\phi=8.90 \times 10^{-5} \mathrm{Fr}_{\min } 5.04
$$

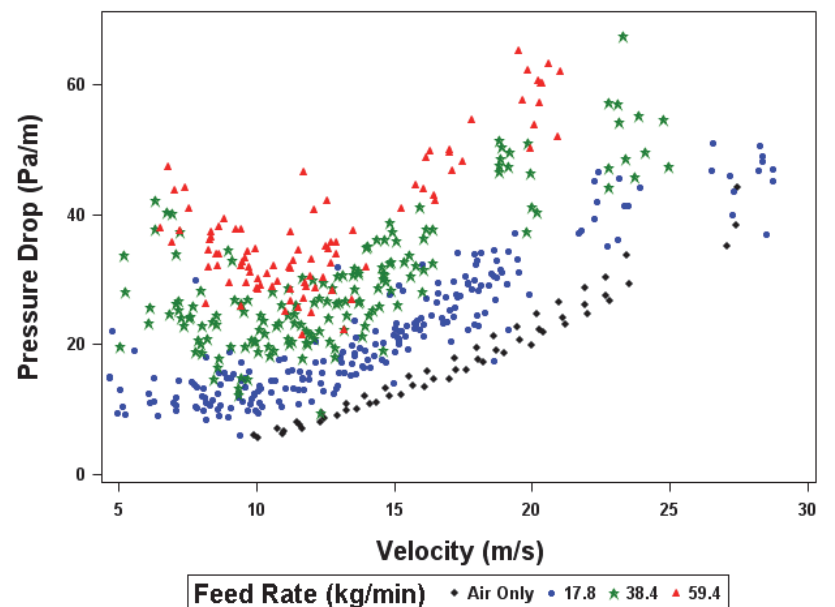

(a)

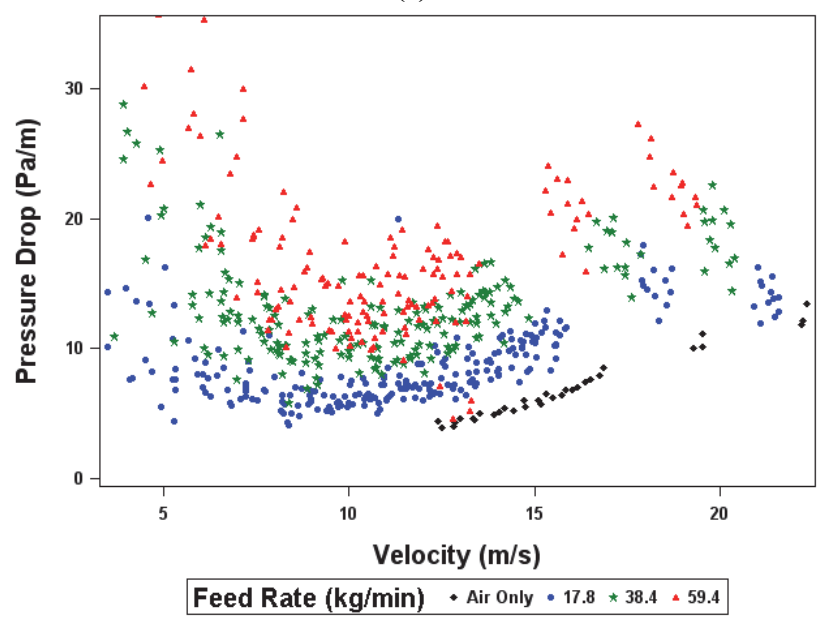

(b)

Figure 4. Pressure drop per unit length for all feed rates in (a) $17.8 \mathrm{~cm}$ pipe and (b) $25.4 \mathrm{~cm}$ pipe.
Substituting the appropriate variables for the mass flow ratio and Froude number at saltation velocity, equation 9 can be solved for the saltation velocity:

$$
v_{s}=4.875 \dot{m}^{0.166} g^{0.417} D^{0.0861} \rho^{-0.166}
$$

where $v_{s}$ is saltation velocity.

Both the pipe diameter $(\mathrm{p}=0.0398)$ and moisture conditioning treatment $(\mathrm{p}=0.0104)$ had a significant effect on the segmented linear model at the $5 \%$ level, while cultivar had no effect. However, the saltation velocities predicted using different models differed little from the saltation velocity predicted by the model developed from regression analysis of all data (eq. 10). Over the range of solids mass flow rates tested, the model for the $17.8 \mathrm{~cm}$ (7 in.) pipe predicted an average saltation velocity $0.4 \mathrm{~m} \mathrm{~s}^{-1}\left(80 \mathrm{ft} \mathrm{min}^{-1}\right)$ higher than the model for all data, the average saltation velocity predicted by the model for the $25.4 \mathrm{~cm}$ (10 in.) pipe was $0.3 \mathrm{~m} \mathrm{~s}^{-1}\left(60 \mathrm{ft} \mathrm{min}{ }^{-1}\right)$ lower than the model for all data, and the individual models for high and low moisture content averaged a $0.2 \mathrm{~m} \mathrm{~s}^{-1}(40 \mathrm{ft}$ $\mathrm{min}^{-1}$ ) deviation in predicted saltation velocity from the model for all data. The predicted saltation velocity for the high moisture content cotton was lower than that for the drier cotton.

The average standard deviation of the measured inlet velocity from the average velocity calculated for each fan speed during each test lot was $0.5 \mathrm{~m} \mathrm{~s}^{-1}\left(100 \mathrm{ft} \mathrm{min}^{-1}\right)$. This variation in the data was primarily due to turbulence and fluctuations in instantaneous feed rates. Since this inherent variation was larger than the differences in saltation velocity predicted by the models for individual treatment levels, these differences between pipe diameters and moisture conditioning treatments were not practically significant. Additionally, statistically significant differences between models are possible even if the predicted saltation velocities are similar, as models could vary significantly in predictions at velocities higher or lower than the saltation velocity. Consequently, equation 10 was used to define the saltation velocity for calculating the resistance factor due to solids for all treatment levels.

The saltation velocity occurred soon after material began to settle on the bottom of the pipe (material flow category C in fig. 5). The values for the coefficients in equation 3 for the boundaries between the material flow categories in figure 5 are shown in table 1.

\section{SOLIDS RESISTANCE FACTOR}

The solids resistance factor (used in eq. 6 to calculate the pressure drop) for velocities higher than saltation was given by the following equation:

$$
\lambda_{s}=0.179 \mathrm{Fr}^{-1}
$$

The $\mathrm{R}^{2}$ value for the model (eq. 6) was 0.91 , and the percent error in predicting the dilute phase pressure drop was $14.2 \%$. Neither diameter $(p=0.637)$, cultivar $(p=0.865)$, nor moisture level $(\mathrm{p}=0.514)$ had an effect on the model. Figure 6 is a plot of the predicted versus actual pressure drop per unit length of pipe, with the 1:1 line shown in black. 


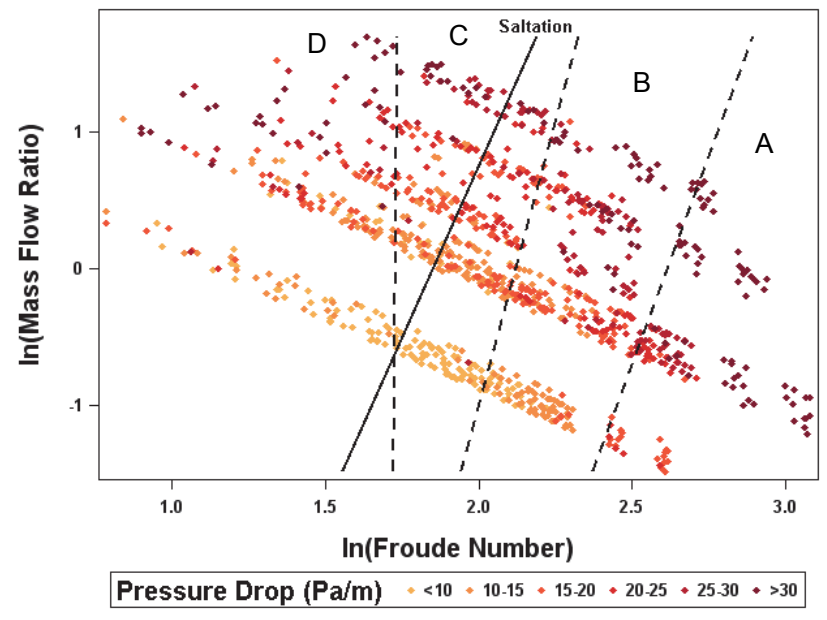

Figure 5. Log transformed mass flow ratio and Froude number with saltation velocity line (solid line) and separating boundaries for different visually observed material flow categories. Marker colors indicate measured differential pressure per unit length $\left(\mathrm{Pa} \mathrm{m}^{-1}\right)$.

Table 1. Boundaries separating visually observed conditions.

\begin{tabular}{|c|c|c|}
\hline \multirow{2}{*}{$\begin{array}{c}\text { Boundaries of Material } \\
\text { Flow Categories }{ }^{[a]} \\
\text { (fig. 5) }\end{array}$} & \multicolumn{2}{|c|}{$\begin{array}{c}\text { Boundary Coefficients } \\
\text { (eq. 3) }\end{array}$} \\
\hline & $\alpha$ & $k$ \\
\hline $\mathrm{A} / \mathrm{B}$ & 6.06 & $1.30 \times 10^{-7}$ \\
\hline $\mathrm{B} / \mathrm{C}$ & 8.31 & $2.24 \times 10^{-8}$ \\
\hline $\mathrm{C} / \mathrm{D}$ & \multicolumn{2}{|c|}{ Vertical line at $\mathrm{Fr}=5.63$} \\
\hline
\end{tabular}

[a] $\mathrm{A}=$ evenly distributed flow, $\mathrm{B}=$ more material in bottom half of pipe, $\mathrm{C}=$ material beginning to settle on bottom of pipe, and $\mathrm{D}=$ settled material forming slugs.

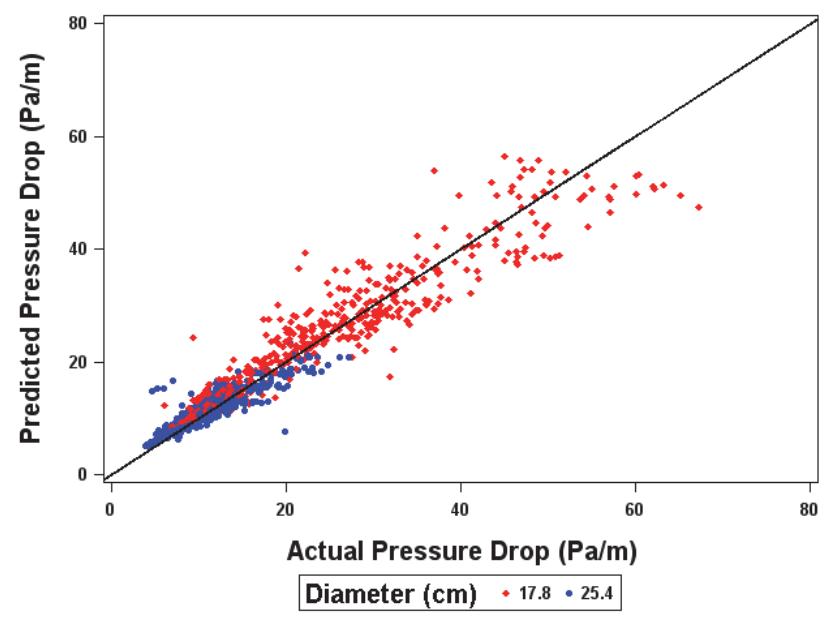

Figure 6. Predicted and actual pressure drop per unit length of pipe (dilute-phase conveying).

\section{DisCUSSION}

For the conditions tested by Mangialardi (1977), equation 10 yielded saltation velocities of $9.51 \mathrm{~m} \mathrm{~s}^{-1}\left(1870 \mathrm{ft} \mathrm{min}^{-1}\right)$ at a mass flow ratio of 1.33 and $9.04 \mathrm{~m} \mathrm{~s}^{-1}\left(1780 \mathrm{ft} \mathrm{min}^{-1}\right)$ at a mass flow ratio of 1.03, compared to Mangialardi's values of $12.7 \mathrm{~m} \mathrm{~s}^{-1}\left(2500 \mathrm{ft} \mathrm{min}{ }^{-1}\right)$ and $9.1 \mathrm{~m} \mathrm{~s}^{-1}\left(1790 \mathrm{ft} \mathrm{min}{ }^{-1}\right)$. Mangialardi's values should be higher because the reported velocity was measured with air only. Due to the additional pressure drop when conveying material, the actual velocity would have been lower, depending on the characteristic fan curve. Furthermore, the velocities reported by Mangialardi were required to maintain a visually observed normal flow (likely corresponding to material flow category A in fig. 5). Mangialardi's description of sluggish flow likely corresponded to material flow category $\mathrm{B}$, while the minimum pressure drop in this study was found to occur at slightly lower velocities than those found in material flow category B.

Mangialardi (1977) found that higher moisture content increased the minimum velocity needed to convey seed cotton, and the practical experience of cotton ginners appears to indicate this as well. However, no practically significant differences occurred between the moisture conditioning treatments in this study. This result was likely due to the smaller range of moisture contents tested $(8.2 \%$ for the seed cotton stored at ambient conditions and $11.1 \%$ for the seed cotton stored at high humidity), while Mangialardi tested moisture content levels as high as $22.5 \%$. The increased minimum conveying velocity reported by Mangialardi for the high moisture content cotton may have actually been due to an increased solids resistance factor. Because the velocities reported by Mangialardi were measured without seed cotton in the conveying system, increased resistance at higher moisture contents would cause a larger drop in the actual velocity when conveying higher moisture content seed cotton than lower moisture content material. The actual air velocities may not have differed when conveying lower or higher moisture content seed cotton. Likewise, a greater pressure drop when conveying higher moisture content seed cotton in gins may result in a lower actual air velocity than with drier seed cotton, leading to the system choking.

Konno and Saito (1969) found that the solids resistance factor was equal to $0.114 \times \mathrm{Fr}^{-1}$ when conveying nearly spherical materials, i.e., glass beads, copper spheres, grass seed, and millet seed (the resistance factor was originally given as $f_{s}=\lambda_{s} / 4$ and converted to $\lambda_{s}$ for comparison). This study indicated that the solids resistance factor of seed cotton was larger, resulting in a higher pressure drop when conveying seed cotton than those other materials. The increased resistance of seed cotton was likely due to increased friction in particle-particle interactions and increased energy lost from impact with pipe walls. This large difference in the solids resistance factor was not surprising, since the primary component of seed cotton, i.e., seeds with many cotton fibers attached, has a considerably different shape than the nearly spherical materials tested by Konno and Saito (1969). Furthermore, seed cotton is not homogenous and also contains leaves, sticks, burs, and soil particles.

\section{IMPLICATIONS FOR COTTON GINS}

An example seed cotton conveying system in a commercial gin may be described by the following parameters:

- $D=0.508 \mathrm{~m}(20 \mathrm{in}$.)

- $\rho=0.95 \mathrm{~kg} \mathrm{~m}^{-3}\left(0.059 \mathrm{lb} \mathrm{ft}^{-3}\right)$, air is heated for drying

- $v=22.9 \mathrm{~m} \mathrm{~s}^{-1}\left(4500 \mathrm{ft} \mathrm{min}{ }^{-1}\right)$

- $\quad \dot{m}=3.7 \mathrm{~kg} \mathrm{~s}^{-1}\left(8.2 \mathrm{lb} \mathrm{s}^{-1}\right)$ or 21 bales h$^{-1}$ with $635 \mathrm{~kg}(1400 \mathrm{lb})$ of seed cotton per bale. 
This mass flow rate results in a mass flow ratio of 0.84 , which corresponds to an air volume to seed cotton mass ratio of $1.25 \mathrm{~m}^{3} \mathrm{~kg}^{-1}\left(20 \mathrm{ft}^{3} \mathrm{lb}^{-1}\right)$, which is the minimum recommended ratio for drying systems (Baker et al., 1994). The calculated pressure drop per unit length due to solids resistance (using eqs. 1 and 11$)$ would be $7.18 \mathrm{~Pa} \mathrm{~m}^{-1}(0.00879$ in. $\left.\mathrm{H}_{2} \mathrm{O} \mathrm{ft} \mathrm{ft}^{-1}\right)$. For a pipe roughness of $0.1 \mathrm{~mm}(0.004 \mathrm{in}$.), the pressure drop per unit length due to air resistance would be only slightly larger at $7.55 \mathrm{~Pa} \mathrm{~m}^{-1}\left(0.00925\right.$ in. $\left.\mathrm{H}_{2} \mathrm{O} \mathrm{ft}{ }^{-1}\right)$. For many conveying systems in gins, the pressure drop due to resistance (both air and solids) in straight pipes is a small part of the total system pressure drop. The pressure loss due to acceleration of material, accessories (such as seed cotton cleaners and cyclones), and elbows often accounts for the majority of pressure loss. The presence of seed cotton will affect the pressure drop in elbows and accessories, but the magnitude of this effect is unknown.

For this seed cotton mass flow rate, pipe diameter, and density, the saltation velocity according to equation 10 would be $14.9 \mathrm{~m} \mathrm{~s}^{-1}\left(2940 \mathrm{ft} \mathrm{min}^{-1}\right)$, significantly less than the actual velocity of $22.9 \mathrm{~m} \mathrm{~s}^{-1}\left(4500 \mathrm{ft} \mathrm{min}^{-1}\right)$. The actual minimum velocity that could be used to convey cotton in a commercial gin system would likely have to be slightly higher to account for the deceleration of material in elbows and fluctuations in air and material flow rate and provide a factor of safety to avoid choking the conveying pipes. The velocity used to convey seed cotton in this example (and most commercial gins) is significantly higher than the saltation velocity to provide adequate drying. However, seed cotton often enters the gin plant at a desirable moisture content for ginning, and drying is unnecessary. In this situation, air velocity could be reduced, resulting in energy savings. For example, a commercial gin may be able to reduce the conveying velocity from $22.9 \mathrm{~m} \mathrm{~s}^{-1}(4500$ $\mathrm{ft} \min ^{-1}$ ) to $10 \%$ above the saltation velocity, or $16.4 \mathrm{~m} \mathrm{~s}^{-1}$ $\left(3230 \mathrm{ft} \mathrm{min}^{-1}\right)$, a $28 \%$ reduction in air velocity.

When the pneumatic conveying system tested in this study was operated at an air velocity of $22.9 \mathrm{~m} \mathrm{~s}^{-1}(4500 \mathrm{ft}$ $\min ^{-1}$ ) and a mass flow ratio of 0.84 , decreasing the air velocity to $16.4 \mathrm{~m} \mathrm{~s}^{-1}\left(3230 \mathrm{ft} \mathrm{min}^{-1}\right)$ reduced the total system pressure drop (measured across the fan) by $37 \%$ with the $17.8 \mathrm{~cm}$ ( 7 in.) conveying pipe and by $43 \%$ with the $25.4 \mathrm{~cm}$ (10 in.) conveying pipe. The electrical power required by the fan was reduced by $52 \%$ and $55 \%$ with the $17.8 \mathrm{~cm}$ (7 in.) and $25.4 \mathrm{~cm}$ (10 in.) pipes, respectively. These decreases in power are $3 \%$ and $4 \%$ lower than what would be expected from the reduction in velocity and pressure drop due to adjustable-speed drive losses and reduced motor efficiency at lower speeds.

The reduced pressure drop resulting from this lower air velocity in a commercial gin would vary, depending on mass flow rate and system design (e.g., number of bends, length of pipe, and dryer, seed cotton cleaner, and cyclone specifications). Significant portions of the seed cotton conveying systems in commercial gins are used to convey air only or air with a small amount of foreign matter removed by the seed cotton cleaners. Consequently, much of the pressure loss in these conveying systems is due to air friction. The reduction in pressure drop and fan power resulting from decreased air velocity at a commercial gin would likely be comparable to the values measured with the pneumatic conveying system tested in this study and may be larger.

Electricity use of individual motors at 15 saw gins and four roller gins was measured by Funk et al. (2013). Seed cotton conveying fans used an average of $7.9 \mathrm{kWh}$ bale $^{-1}$ at saw gins and $16.2 \mathrm{kWh}$ bale $^{-1}$ at roller gins (P. A. Funk, USDA-ARS, unpublished data; in the manuscript, fans are included under the categories for seed cotton drying, unloading, and conveying). If the air velocity was also reduced by $28 \%$ at these commercial gins, and the resulting reduction in electricity use was the same as the average value for the conveying system tested in this study $(53.5 \%)$, the electricity savings would average $4.2 \mathrm{kWh} \mathrm{bale}^{-1}$ for saw gins and 8.7 $\mathrm{kWh} \mathrm{bale}^{-1}$ for roller gins. These savings represent $12 \%$ and $16 \%$ of the total average electricity use at saw gins and roller gins, respectively.

One potential issue with reducing seed cotton conveying velocities is that cyclones are used to remove dust from fan exhausts at cotton gins. Cyclone inlet velocities are typically specified by air pollution regulatory agencies. Regulations vary among states but typically only allow a variation of $10 \%$ to $20 \%$ from the design inlet velocity. However, recent research has shown that cyclone efficiency may be maintained at lower inlet velocities (Funk et al., 2000; Faulkner and Shaw, 2006).

The models developed in this study will enable the development of fan speed control systems for pneumatic conveying in cotton gins. These systems will use lower air velocities under appropriate conditions, thus reducing energy use, and should reduce the likelihood of choking the conveying pipes during adverse conditions, such as seed cotton with high moisture content. These models indicate that the seed cotton mass flow rate and air density (primarily affected by temperature) are critical input variables for a control system. While no commercial system exists for measuring seed cotton mass flow rate, several potential methods have been recently tested (Sui and Byler, 2012; Hardin, 2013). Additionally, the relationship between pressure drop and air velocity could also be used in a control system. With a constant mass flow rate, a decrease in air velocity will also reduce the pressure drop per unit length of pipe until the saltation velocity is reached. A fan speed control system would need to be integrated with seed cotton drying system controls to ensure that an adequate air volume was available for drying.

\section{CONCLUSION}

The pressure drop per unit length of pipe measured while conveying seed cotton decreased with decreasing velocity, reached a minimum, and then increased until the conveying pipe choked. Higher seed cotton mass flow rates increased the pressure drop at all velocities. The saltation velocity, corresponding to the velocity at the minimum pressure drop, was identified by fitting a segmented linear model to the log transformed data $\left(\mathrm{R}^{2}=0.88\right)$. The resulting relationship between the mass flow ratio and the Froude number at saltation velocity was: $\phi=8.90 \times 10^{-5} \times \mathrm{Fr}_{\min }{ }^{5.04}$. This equation predicted a saltation velocity of $14.9 \mathrm{~m} \mathrm{~s}^{-1}\left(2940 \mathrm{ft} \mathrm{min}^{-1}\right)$ with a mass flow rate of $3.7 \mathrm{~kg} \mathrm{~s}^{-1}\left(8.2 \mathrm{lb} \mathrm{s}^{-1}\right)$, a pipe diameter of $0.508 \mathrm{~m} \mathrm{(20}$ 
in.), and a density of $0.95 \mathrm{~kg} \mathrm{~m}^{-3}\left(0.059 \mathrm{lb} \mathrm{ft}^{-3}\right)$, conditions similar to a commercial gin. Pipe diameter and moisture content had a statistically significant effect on the model used to predict saltation velocity; however, these differences were not practically significant.

The solids resistance factor for dilute-phase conveying, with velocities greater than saltation, was found to be 0.179 $\times \mathrm{Fr}^{-1}$. The $\mathrm{R}^{2}$ value for this model was 0.91 , and the percent error in predicting the differential pressure drop per unit length was $14.2 \%$. Diameter, cultivar, and moisture content had no effect on the model for the solids resistance factor. With a mass flow rate of $3.7 \mathrm{~kg} \mathrm{~s}^{-1}\left(8.2 \mathrm{lb} \mathrm{s}^{-1}\right)$ and a pipe diameter of $0.508 \mathrm{~m}$ (20 in.), the pressure drop per unit length due to solids resistance would be $7.18 \mathrm{~Pa} \mathrm{~m}^{-1}(0.00879$ in. $\mathrm{H}_{2} \mathrm{O} \mathrm{ft} \mathrm{ft}^{-1}$ ), nearly as large as the pressure drop due to air alone in the same pipe at typical gin operating conditions. The models developed in this study may be useful in designing control systems for cotton gin conveying systems, resulting in potentially significant electricity and cost savings.

\section{ACKNOWLEDGEMENTS}

The author wishes to thank Debbie Boykin, USDA-ARS MSA statistician, for assistance with the statistical analysis, and the staff of the USDA-ARS Cotton Ginning Research Unit for assistance in conducting this study.

\section{REFERENCES}

Baker, R. V., Columbus, E. P., Eckley, R. C., \& Stanley, B. J. (1994). Pneumatic and mechanical handling systems. In Cotton Ginners Handbook (pp. 143-171). Washington, D.C.: USDA Agricultural Research Service.

Barth, W. (1954). Stromungstechnische probleme der verfahrenstechnik. Chem. Ing. Tech., 26(1), 29-34.

Byler, R. K., \& Anthony, W. S. (2000). Cotton moisture content sensing for gins using resistance. In Proc. Beltwide Cotton Conf. (pp. 1561-1564). Memphis, Tenn.: National Cotton Council.

Chand, P., \& Ghosh, D. P. (1968). Critical analysis of pressure drop under pneumatic conveyance of solids. J. Agric. Eng. Res., 13(1), 36-43. http://dx.doi.org/10.1016/0021-8634(68)90118-2.

Crane, J. W., \& Carleton, W. M. (1957). Predicting pressure drop in pneumatic conveying of grains. Agric. Eng., 38(3), 168-171, 180.

Faulkner, W. B., \& Shaw, B. W. (2006). Efficiency and pressure drop of cyclones across a range of inlet velocities. Appl. Eng. Agric., 22(1), 155-161. http://dx.doi.org/10.13031/2013.20191.

Funk, P. A., \& Hardin IV, R. G. (2012). Cotton gin electrical energy use trends and 2009 audits. Appl. Eng. Agric., 28(4), 503-510. http://dx.doi.org/10.13031/2013.42078.

Funk, P. A., Hughs, S. E., \& Holt, G. A. (2000). Entrance velocity

optimization for modified dust cyclones. J. Cotton Sci., 4(3), 178-182.

Funk, P. A., Hardin IV, R. G., Hughs, S. E., \& Boykin, J. C. (2013). Changes in cotton gin energy consumption apportioned by 10 functions. J. Cotton Sci., 17(3), 174-183.

Hardin IV, R. G. (2013). Determining seed cotton mass flow rate by pressure drop across a blowbox. In Proc. Beltwide Cotton Conf. (p. 990). Memphis, Tenn.: National Cotton Council.

Hardin IV, R. G., \& Funk, P. A. (2012). Electricity use patterns in cotton gins. Appl. Eng. Agric., 28(6), 841-849. http://dx.doi.org/10.13031/2013.42471.

Hardin IV, R. G., \& Funk, P. A. (2013). Energy monitoring in gins:
2012 preliminary results. In Proc. Beltwide Cotton Conf. (pp. 972-977). Memphis, Tenn.: National Cotton Council.

Hinds, M. A., \& Milliken, G. A. (1987). Statistical methods for using nonlinear models to compare silage treatments.

Biometrical J., 29(7), 825-834.

http://dx.doi.org/10.1002/bimj.4710290711.

Holt, G. A., Laird, J. W., Baker, R. V., \& Funk, P. A. (2001). Calculated versus measured pressure losses for two seed cotton unloading systems. Appl. Eng. Agric., 17(4), 465-473. http://dx.doi.org/10.13031/2013.6463.

Jones, P. J., \& Leung, L. S. (1978). A comparison of correlations for saltation velocity in horizontal pneumatic conveying. Ind. Eng. Chem. Proc. Design and Development, 17(4), 571-575. http://dx.doi.org/10.1021/i260068a031.

Klinzing, G. E., Rizk, F., Marcus, R., \& Leung, L. S. (2010). Pneumatic Conveying of Solids: A Theoretical and Practical Approach (3rd ed.). New York, N.Y., N.Y.: Springer. http://dx.doi.org/10.1007/978-90-481-3609-4.

Konno, H., \& Saito, S. (1969). Pneumatic conveying of solids through straight pipes. J. Chem. Eng. Japan, 2(2), 211-217. http://dx.doi.org/10.1252/jcej.2.211.

Mangialardi Jr., G. J. (1977). Conserving energy: Reduce volume of air to transport and dry seed cotton. Texas Cotton Ginners $J$. Yearbook, 45(1), 13-16.

Matsumoto, S., Harada, S., Saito, S., \& Maeda, S. (1975). Saltation velocity for horizontal pneumatic conveying. J. Chem. Eng. Japan, 8(4), 331-333. http://dx.doi.org/10.1252/jcej.8.331.

Mewing, S. F. (1976). BE thesis. Brisbane, Queensland, Australia: University of Queensland.

Person Jr., N. K., \& Sorenson Jr., J. W. (1966). Pneumatic handling of sorghum grain. Trans. ASAE, 9(2), 238-241. http://dx.doi.org/10.13031/2013.39938.

Rizk, F. (1976). Pneumatic conveying at optimal operation conditions and a solution of Barth's equation. In Proc. Pneumotransport 3, Paper D4. Cranfield, U.K.: BHRA Fluid Engineering.

Shepherd, J. V. (1972). Standard procedures for foreign matter and moisture analytical tests used in cotton ginning research. Washington, D.C.: USDA Agricultural Research Service.

Sui, R., \& Byler, R. K. (2012). Evaluation of a mass flow sensor at a gin. J. Cotton Sci., 16(1), 27-33.

Valco, T., Ashley, H., Green, J., Findley, D., Price, T.., Fannin, J., \& Isom, R. A. (2012). The cost of ginning: 2010 survey results. In Proc. Beltwide Cotton Conf. (pp. 616-619). Memphis, Tenn.: National Cotton Council.

Welschof, G. (1962). Pneumatische förderung bei großen fördergutkonzentrationen. VDI Forschungsheft, 492, 18-26. Düsseldorf, Germany: VDI Verlag.

Zenz, F. A. (1949). Two-phase fluid-solid flow. Ind. Eng. Chem., 41(12), 2801-2806. http://dx.doi.org/10.1021/ie50480a032.

Zigrang, D. J., \& Sylvester, N. D. (1982). Explicit approximations to the solution of Colebrook's friction factor equation. AIChE J., 28(3), 514-515. http://dx.doi.org/10.1002/aic.690280323.

\section{NOMENCLATURE}

$A=$ cross-sectional area of pipe $\left(\mathrm{m}^{2}\right)$

$c_{1}$ to $c_{6}=$ parameters in segmented linear model

$D=$ pipe diameter $(\mathrm{m})$

$\mathrm{Fr}=$ Froude number related to air velocity, $v(g D)^{-0.5}$

$\mathrm{Fr}_{\text {min }}=$ Froude number at saltation velocity, $v_{s}(g D)^{-0.5}$

$g=$ gravitational constant $\left(9.81 \mathrm{~m} \mathrm{~s}^{-2}\right)$

$k=$ parameter in saltation velocity model

$L=$ length of pipe (m)

$\dot{m}=$ solids mass flow rate $\left(\mathrm{kg} \mathrm{s}^{-1}\right)$ 
$\mathrm{Re}=$ Reynolds number, $\rho v D \mu^{-1}$

$s=$ proportionality constant for solids resistance

$v=$ air velocity $\left(\mathrm{m} \mathrm{s}^{-1}\right)$

$v_{s}=$ saltation velocity $\left(\mathrm{m} \mathrm{s}^{-1}\right)$

$\alpha=$ exponent in saltation velocity model

$\Delta p=$ pressure drop
$\Delta p_{s}=$ pressure drop due to solids

$\varepsilon=$ pipe absolute roughness $(\mathrm{m})$

$\phi=$ mass flow ratio, $\dot{m}(\rho A v)^{-1}$

$\lambda_{a}=$ resistance factor for air

$\lambda_{s}=$ resistance factor for solids

$\mu=$ dynamic viscosity (Pa s)

$\rho=\operatorname{air}$ density $\left(\mathrm{kg} \mathrm{m}^{-3}\right)$ 